\title{
A Strategy For Innovation Development Of Service Business For Older Persons
}

\author{
Kietchai Veerayannon, (E-mail: Kietchai@truemail.co.th), Suan Dusit Rajabhat University, Thailand.
}

\begin{abstract}
The objective of this research is to present a strategy for innovation development of service business for older persons. The research is a qualitative research. The researcher had planned and studied from the related topic documentary, in-depth interview and focus group. From the research findings, the researcher presented a model of service business for older persons called "PARADISE". It is a peaceful and private residence located among nature and equipped with physical facilities for aging people to live happily as well as some recreational activities for entertainment. This place also builds a warmth-hearted society and good environment for aging people to feel free and cheerful in their living. In addition, a strategy called "FINALE-HOME" would lead the service business for aging people to be successful through a significant factor of good management.
\end{abstract}

\section{INTRODUCTION}

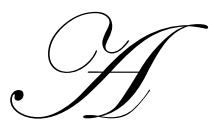

ccording to the world population record in 1999, the United Nations estimated the increase in population of every age worldwide from 4,100 million to 8,200 million for the 50 years (1975-2025) period or increasing $100 \%$. Meanwhile, the population aging over 60 years has greatly increased from 350 million to 1,100 million or increasing $224 \%$. Presently, most of people aging nearly 60 years were born in the baby boom period during 1946-1964. The figures reflect the lower dying rate as a result of the advance medical technology helping people to live longer. So the number of aging people has apparently increased in every country.

In Thailand, the rate of aging population has tendency to increase every year. The life expectancy at birth of Thai people is higher (averaging 74.9 years for women and 69.9 years for men). Meanwhile, the rate of new born baby has decreased. In 2005, the number of aging people was 6.69 million or $10.17 \%$ of total population of 65.25 million (National Statistics, 2005).

Normally, people at old age have free times and health problems, but they are lack of care by their children because most of young people are struggling with economics (Peter, 2003). Presently, many countries have concentrated to the increasing rate of aging population in social, legal and business perspectives. It anticipates that the service business related to older persons has an opportunity to grow rapidly in the future. These businesses are hospitals, nursing home, further education and recreational services (Drucker, 1994).

The services for older persons in Thailand can be classified into three groups: 17 residential home for aging persons operated by Department of Social Development and Welfare under supervision of Ministry of Social Development and Human Security for self-reliant older persons living away from family; the projects operated by the charities, namely the Thai Red Cross's "Sawangkhanives" project; and the nursing home operated by private companies. However, the current services for older persons provided by the government, charities or private companies are insufficient (The Thailand's News Direction Project, June 2003). Consequently, the researcher was interested to find a business model to serve directly the demands of the older persons. It is modern and valued service business because there is a growing trend towards the service business for older persons. 


\section{OBJECTIVES OF THE RESEARCH}

1. To study activities of current service business for older persons

2. To study demands of older persons for services

3. To find out a guideline for development of business concept to be modern and value which serve the demand of the older people

4. To study obstacles, restrictions and factors to be successful in the service business for older persons

5. To present the strategy for innovation development of service business for older persons

\section{REVIEW OF LITERATURE}

There were theories of service marketing, the psychology in aging people, the articles about the current service business for older persons and the scholar's researches about the aged.

\section{RESEARCH FRAMEWORK} follows:

From the literature review, the researcher integrated principles and thoughts to scope ideas of the research as

1. Nature and demands of the aged

2. Modern family's caring for aging persons

3. Thai social values and culture in caring parents

4. Innovation of the service business for the aged in Thailand and overseas

5. Problems, obstacles, restrictions and elements effecting to the achievement of the service business for the aged

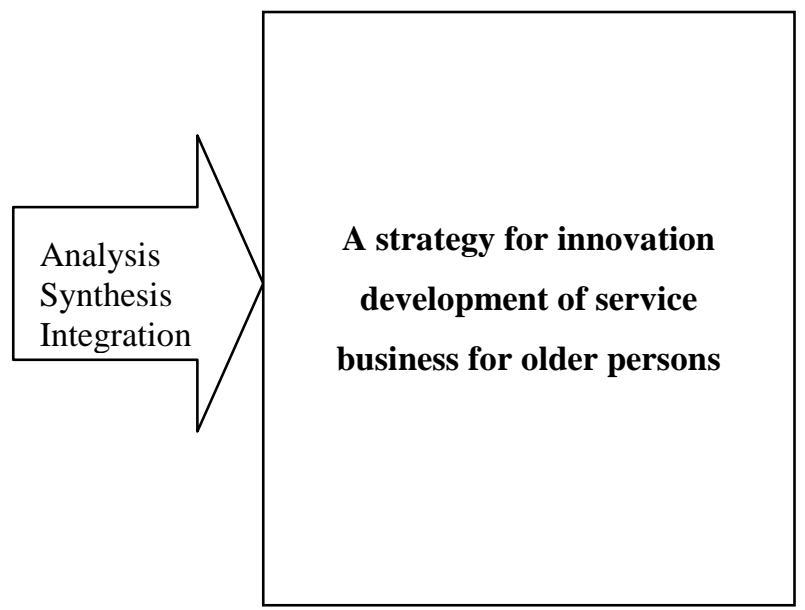

\section{SCOPE OF RESEARCH}

The scope of research consisted of the factors in the research framework, which had been analyzed, synthesize and integrated to be a strategy of the service business for older persons.

The key informants were scoped with persons related to services for the aged such as the manager of nursing home, the business operator of residential estate for the aged, the scholar studying about the aged, the aged their relatives, and the aging people's caretaker.

The research was conducted during January-September 2006. 


\section{BENEFITS FROM THE RESEARCH}

1. To apply the findings from the research such as information, problems and obstacles to integrate as a strategy in developing the service business to meet the demands of older persons

2. To improve current service business to respond demands of older persons

3. To apply the findings for other services to helpless or general persons

4. To apply the findings for helping aging persons in community to reduce social problems

\section{RESEARCH METHODOLOGY}

The research was a qualitative research. The researcher had planned and involved in the documentary study, in-depth interview and focus group. The key informants consisted of people that were the management team or the owner of service businesses such as hospitals and private nursing homes, the academics and the older persons. The individual interview was undertaken with these 39 key informants. In addition, the focus group meetings were held with five aging people's caretakers who had worked for nursing home not less than 1.5 years as well as 10 descendants and relatives of the aged; and 8 pre-old and older persons. The total numbers of key informants were 62 . The contents of in-depth interview and topic of focus group meetings covered all objectives and framework of the research. The researcher collected information without bias and checked data by using the Triangulation method. The information was analyzed according to the related theories and experiences of the experts and advisors. So the information was confirmed to be reliable. The research findings were from analysis, synthesis and integration with the theory of service marketing to be a strategy of the service business for older persons. The research was presented in a form of descriptive report.

\section{FINDINGS OF THE RESEARCH}

\section{Current Models of Service Business for Older Persons}

According to the study of the innovation of service business for older persons, for both domestic and overseas market, it found that the service business for older persons in overseas has been developed more advance than Thailand because the becoming of aging society in overseas has been earlier realized, such as in USA and Japan, we can find several types of service business, including Health and Fitness, Financial Planning, Traveling, SeniorCourse Computer Training, Home Instead Senior Care, Nursing Home, and Companionship and Domestic-Care Service (Swartz, 1999). In particular, the business of elderly housing is more popular and becomes the Senior Welfare Industry. Consequently, presently, in USA there is Life Care Community not less than 2,300 communities (Kim, Kim, and Kim 2003).

The service business for older persons in Thailand can be categorized into three groups as follows:

First Group: The 17 residential homes for aging persons managed by Department of Social Development and Welfare under supervision of Ministry of Social Development and Human Security namely the Vassanaves and Ban Bang Khae and 14 service centers for the aged nationwide.

Second Group: The residential homes managed for charities such as Thai Red Cross's "Sawangkhanives" building in Samutprakarn and the St Camillo Foundation's residential homes in Prachinburi, Nakhonpathom and Chanthaburi province.

Third Group: The service business for the aged operated by private companies such as nursing homes and the sole residential estate project for the aged with health services in Bang Sai District, Phra-Nakorn-Sri-Ayutthaya province. 


\section{Demands of Older Persons for Services}

Currently, there is the tendency of the increase of single family, small size family, and the change of economic situation causing that the member of each family needs to work and leaves older people at home. Therefore, the present and future of Thai society will increasingly consist of spiritless old people (Keawkungwal, 2006).

Most of the Thai older persons in general requires happiness in life through a living with family and children, making the Buddha worship, having a peaceful and social life, having enough money for self-spending, being healthy and sacrificed, giving contribution to society, doing good things and being free from liabilities.

However, each older person has different demands, which these depends on age and individual background. Some older persons who can be self-reliant do not require any assistance, but they look for happiness themselves after the retirement such as doing favorite activities, traveling, exercising, playing music, making merits and joining with friends and social activities for contribution. They need freedom and being accepted as valued persons. On the other hand, the old persons who sometime cannot help themselves need someone to take care of such as doing housework or being accompanied. For the helpless old persons whose health is very weak and sometime acting like a child, they need someone to look after all the times. The aged is similarly emotional, but they need understanding and love from someone they care. Therefore, the living in good quality and environment is necessary for the aged. Being old age is a fact that people cannot avoid so everybody should prepare to be old by taking care of own health. Dharma also teaches the aged to understand better about mortal life so they can adapt the instructions for them to live peacefully.

\section{Development of Modern and Value Service Business for Older Persons}

The services for the aged in each nation are different depending on social values and cultures. In Thailand, the rate of aging population is increasing so the concept of service business for the older persons is widely considered. However, the project relating to the aged has to concentrate on safety of the buildings as well as creating a warm feeling of the family and relaxation. The services should provide physical, mental, social and spiritual encouragement. The aged are also entertained by some recreational activities covering all demands of them, including the needs of private freedom and good society, especially their needs of love and understanding. In addition, this service business must be well-organized.

The findings indicated the modern family's caring for the aged. The key informants believed in Thai and Chinese-Thai social values and culture in gratitude towards the older persons. These values prevented the children from sending their old parents to be taken care by others. However, the aged treatment in Thailand has changed because of the economic conditions that young people have to work hard and are lack of time to look after their old parents. It is also difficult to find a reliable servant to look after their old parents. In addition, the young people prefer to have single family without the older generation. Therefore, the aged treatment becomes the responsibilities of the nursing home or the aged caring home service. Before calling services from these operators, the children should consider about the readiness and necessity of their old parents to be taken care by unfamiliar persons. Love and warmth in family together with the safety of their parents and expenses are also significant factors that the children should concern before selecting the aged caring home service or nursing home for their old parents.

From the above-mentioned findings, the key informants also believed that Thai aging persons needed to live with their children in familiar location. Moreover, the older Thai persons tended to spend less money, but saving for their children. Therefore, the relocation of the old parents should come from their will. To move to the care center should gradually do in order to preserve the old parents' feelings that they are not abandoned by their children. Love and warmth in family are also still given to them by their children.

The older persons should be treated well and be happy wherever they are at home or outside the house. It is necessary that the person who looks after the older person must be optimistic. In addition, the children should be taught to be grateful to their parents by caring them when getting old. The gratitude cannot be replaced by money so the children should express their strong intention in caring their old parents. Consequently, the good value of gratitude should be practiced by the younger generation to the older generation. 
The development of service business for the older persons according to Thai culture is sensitive. The business goal and advantages must be clearly seen and do not conflict to the emotion of younger generation. The operation of this service business has to concern about caring, which is blended well with Thai traditions and culture.

\section{Problems, Obstacles, Restrictions and Factors to Bring the Service Business Successful}

\section{Problems and Obstacles}

1) The dying age of old persons is unpredictable so the financial plan and the current of assets cannot be managed as planned. 2) The target group is limited only the high-end customers while the business operator gains less profit and turnover. 3) Higher production cost for the business projects located near urban areas.4) High personnel turnover rate because the caring services for the aged is hard. 5) Some aging persons have psychic problems such as amnesia, self-assault or harming the others so the psychologist is needed. 6) Over expectation from relatives of the aged for the caring services. 7) The different status of customers may cause conflicts. 8) Most people believe that this service business must be operated by doctors. 9) Operation of the service business must be complied with the laws. 10) Conservation of the business style to be implemented in long-term. 11) Maintenance problems 12) The service business for older persons do not generate high profit as estimated.

\section{Factors to Succeed}

1) Understanding the demands of aging persons 2) Creating new service innovation 3) Strong financial management 4) Good marketing plans 5) Right location 6) Reasonable price 7) Selection of the target group 8) Excellent services 9) Build the customers' confidence for the services 10) Having the business alliances 11) The management team is able to live with aging persons 12) Having love and mercy 13) Good working system 14) Good management system 15) Having morality and ethics 16) Conducting a market research before investment .

\section{Presentation on a Strategy for Innovation Development of Service Business for Older Persons}

The research findings indicated not only the demands of older persons but also the potential of this service business to serve these demands. However, the operation of service business for the aged accordingly to Thai culture is rather sensitive. The operator should consider about love and care, being family, and the value of gratitude to parents. Therefore, the factor of strategy for innovation development is necessary to be complied and applicable with Thai Consumer Behavior since the consumers are seeking and evaluating the service which can satisfy their needs (Schiffman and Kanuk, 1994: p.7). In other words, the consumer behavior directly has an effect on the strategy of the service business as well as the business success. We can see that if the strategy can support the customer's satisfaction, the warm hospitality service under Thai culture is the impact factor of Thai older persons' decision. Thus, the marketer needs to properly launch the strategies that can encourage and satisfy the consumer. In addition, the marketer should search for the internal feeling or the secret black box of the older consumers and evaluate which factors is the key impact of their decisions. The impact factors consist of Cultural Factor, Social Factor, Personal Factor and Psychological Factor (Kotler, 1997: p 174).

The businessman should realize the philosophy is that "Human beings should be treated with care for entire lives." Consequently, the service provider should have long-term visions in developing the project to be up-to-date and valuable in order that the service can serve the demand of the aged in living happily for their remaining lives. This is because the developing process is to modernize and the developed process is the modernization (Myrdal, 1968). Moreover, the business operator and staff should be responsible to provide best services with love and care for every older person living in the project. The happiness of customers is a goal of the business. The operator does not take advantages from the needs and necessity of the aged.

Accordingly to the indicated finding, the researcher presented an integrated business model called PARADISE. It is a beautiful residential project for aging persons where they can live happily. Each alphabet refers to the meanings as follows: 


\begin{tabular}{rll} 
& Refer to & Meanings \\
\hline $\mathrm{P}=$ Physical Health & Physical facilities of all projects supporting good health \\
$\mathrm{A}=$ Activity Complex for Happiness & $\begin{array}{l}\text { A center of recreational activities to entertain the aging } \\
\text { persons being happy }\end{array}$ \\
$\mathrm{R}=$ Relaxation with Nature & A place for relaxation closing with nature \\
$\mathrm{A}=$ Alive and Fresh & A lively and cheerful place \\
$\mathrm{D}=$ Dynamic Community & An active and motivated community \\
$\mathrm{I}=$ Independent and Private Living & Feeling free when living in this place \\
$\mathrm{S}=$ Social getting Together & A warm-hearted society \\
$\mathrm{E}=$ Environmental Excellence & Environment is excellent.
\end{tabular}

PARADISE is a business model equipped with convenient physical facilities for aging people to live with happiness for their good physical and mental health as well as living in a warm-hearted society. The project consists of recreational building where some activities for aging people are available for entertainment. These activities help the aged to be active and spirit. In addition, the residence is peaceful and safe located privately among nature. The place is suitable for relaxation as well as giving cheerful and free senses. People in this society are friendly and warmhearted so the aged can spend their times in good environment with beautiful scenery.

The researcher also presented a strategy called FINALE-HOME as factors for the success of service business for older persons. The FINALE-HOME refers to a living home filling with love and warmth where the house owner lives happily for entire life. Each alphabet has meanings as follows:

\begin{tabular}{|c|c|c|c|}
\hline & & Refer to & Meanings \\
\hline \multirow[t]{2}{*}{$\bar{F}$} & $=$ & Finance & Firm financial plan of the project owner and customers \\
\hline & $=$ & Flexibility & Flexibility in operations \\
\hline \multirow[t]{2}{*}{ I } & $=$ & Innovation & Frequently creating new services \\
\hline & $=$ & Integration & Integration of service and personnel management systems \\
\hline \multirow[t]{2}{*}{$\mathrm{N}$} & $=$ & Nursing & Good quality of nursing services \\
\hline & $=$ & Nicety & Having mercy, friendship and efficiency \\
\hline \multirow[t]{2}{*}{ A } & $=$ & Assurance & Building the customers' confidence in services \\
\hline & $=$ & Alliance & Having alliances with related businesses \\
\hline \multirow[t]{2}{*}{$\mathrm{L}$} & $=$ & Love & Services provision with love and care \\
\hline & $=$ & Luxury & Being luxurious in appropriated with the customers' status \\
\hline \multirow[t]{2}{*}{$\mathrm{E}$} & $=$ & Entertainment & Offering entertainment to customers \\
\hline & $=$ & Empathy & Sharing the customers' feeling as if they were your own \\
\hline \multirow[t]{2}{*}{$\mathrm{H}$} & $=$ & Help & Giving assistance \\
\hline & $=$ & Humanity & Being respectful to human dignity \\
\hline \multirow[t]{2}{*}{$\mathrm{O}$} & $=$ & Organization & Being well-organized \\
\hline & $=$ & Optimization & Having appropriate decision making in operation \\
\hline \multirow[t]{2}{*}{ M } & $=$ & Marketing & Having strong marketing strategy \\
\hline & $=$ & Management & Having good-systematic management \\
\hline \multirow[t]{2}{*}{$\mathrm{E}$} & $=$ & Esteem & Being respectful to older persons \\
\hline & $=$ & Ethics & Operating business based on morality, honor and ethics \\
\hline
\end{tabular}

FINALE-HOME is a strategy to lead this service business being successful. The keys are the preparation of firm financial plan with flexible business operations as well as new service innovation and the integration of working and personnel systems. In accordance with Chaoprasert (2003), the satisfaction and the behavior of each customer are definitely different; however, they can be grouped. Also, the change of customer's need and behavior will cause the improvement and development of the service and consequently comply with the satisfaction. Moreover, it is found that some behaviors might be changed when the new and satisfied service is provided. In other words, customer's 
satisfaction is unlimited. Besides, we can see, regularly, that customer cannot present their direct requirements and behaviors since there are further requirements such as the requirement of convenience, readiness, and steadiness. In particular, the requirement of health, modernization and worthiness is significantly concentrated. In addition, the services given to aging people must be undertaken with love, mercy, friendship and care. So the building of good relationship between the aged customers and staff is significant, similarly to having business alliances. Meanwhile, the project facilities have to be luxurious being suitable for the customers' status, and also providing recreational activities to entertain them. Particularly, the customers must be treated well and appropriated. The management and operating systems must be well-organized in parallel with a strong marketing plan. Finally, the business operation should maintain in good governance.

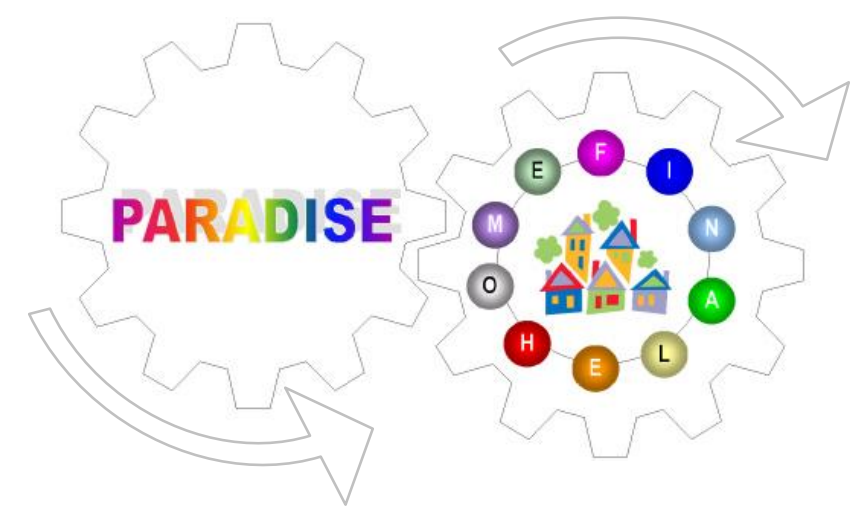

Consequently, PARADISE and FINALE-HOME can be compared as a machine, which it can work by the proper running of every part. Similarly to the service business for aged people will be successful based on the abovementioned elements. Danthamrongkul (2004) mentioned that the good quality service generates the customer's satisfaction and consistent profit which are the well related elements as shown in Service Profit Chain.

\section{SUMMARY OF THE RESEARCH}

The service business for older persons in Thailand can be categorized into three groups that are residential homes and service centers for the aged nationwide operated the government agency; the residential homes for the aged operated by the charities such as Thai Red Cross and the St. Camello Foundation of Thailand; and the nursing home and residential estate for the aged operated by private companies.

The general demands of older persons are a living closely with family, a peaceful life, having friends and social life, having enough money for spending, being healthy, and making contribution to society. In addition, some self-reliant older persons look for happiness after the retirement. They need some recreation activities to entertain themselves. They also want their values to be accepted as well as freedom in living. However, the aging persons who sometime cannot help themselves require someone to take care while the helpless aging persons whose health are very weak need someone to look after all the times. Furthermore, all older persons are similar in needing love and care.

The service business for older persons varies in each nation because of different social values and culture. The establishment of this service business in Thailand tends to grow due to an increase rate of aging population. The commercial projects for serving the aged must be proper and safe. Some recreational activities should be available at the project for aging persons to exercise and be enjoyable. The location of project should be beautiful and full of warmth like living with family. Moreover, the social environment must be good. The operator realizes that Thai older persons have beliefs in love and care from their children. Consequently, this service business should be developed accordingly with Thai tradition and culture. 
Problems and obstacles in operating this service business are unexpected dying age of aging persons, purchasing power of customers, high personnel turnover, the over expectation of aging person' relatives for services, the customer's confidence, the legal problems and the long-term business conservation. Perhaps, this service business does not generate high profit while the turnover may take time.

The factors for the achievement of service business for older persons consist of the understanding in demands of aging persons, creating new innovation to serve these demands, clear business model, strong financial and marketing plans, and best services with love and care to build the customer's confidence. In addition, the alliance, good management system and ethics support business to progress.

The visions of this business base on modernization both in services and values. Consequently, the researcher presented the model of service business for older persons called "PARADISE" along with a strategy for success called "FINALE-HOME". These business model and strategy work together to achieve the business goals.

\section{RECOMMENDATION}

\section{Recommendation For Business Implementation}

1. The businessman should conduct marketing research before investment because the demands of older persons in different ages are various. Moreover, the aged who live alone and have not children are also the potential target group.

2. When providing services for foreign customers, the businessmen should know well about the customers' social values and culture, which those are different in each nation.

3. The government should promote the service business for older persons because this business can relieve the burden of caring aging population. The government's support may be tax assistance, issuing regulations useful for the operation of nursing home, or easing immigrant process for foreigners who want to use this service in Thailand.

4. The government should encourage labor force in this business field by promoting the knowledge of the aged treatment to be widely practiced in educational institutions and families. As a result, the practical knowledge in this field becomes a career.

5. The government should establish a long-term plan for helping the aging population. The plan may include the systematic solution of the aged treatment, the preparation for being old since childhood and the improvement of Thai public health structure.

6. People should encourage the values of gratitude that the children must treat older persons well. This also creates warmth in family.

7. Children should be advised to join activities in helping the aged.

\section{Recommendation For Further Study}

1. A research and a cultural campaign should be conducted to change impractical social values and attitudes about the aged treatment in Thailand.

2. A research should be conducted to set standard of the aged treatment in Thailand.

3. A research should be conducted to find out the proper saving plans for the retirement as well as introducing activities to promote the significance of savings for the retirement. 


\section{REFERENCES}

1. Chaoprasert, C. (2003). Services Marketing. Se-Education Public Co., Ltd. Bangkok 2003, page 18-20.

2. Danthamrongkul, W. (2004). The Heart of Service. Se-Education Public Co., Ltd. Bangkok 2004.

3. Drucker P. F. (1994). The Age of Social Transformation. The Atlantic Monthly 11/1994.

4. Keawkungwal, S. (2006). The Psychology of Life Development: Teenager to Older Persons, $9^{\text {th }}$ Publishing, Thammasart Press 2006.

5. Kim, S., Kim, H. and Kim, W.G. (2003). Impacts of senior citizens' lifestyle on their choices of elderly housing. Journal of Consumer Marketing Vol.20 No.3, 2003 pp. 210-226.

6. Kotler, P. (1977). Marketing Management: Analysis, Planning, Implementation. and Control, 3rd ed. Upper Saddle River, NJ: Prentice Hall.

7. Myrdal, G. (1968). Asian Drama: An Inquiry into the Poverty of Nations. Harmondsworth: Penguin, Vols. I-III

8. National Statistical Office, Population and Housing Census. (2005). [On-line]. Available : http://www.nso.go.th [2005, January 26].

9. Peters, T. (2003). Re-imagine!. Donnelleys in the USA and Star Standard in Singapore, 2003.

10. Quinn, J.B. (1980). Strategies for Change: Logical Incrementalism. Richard D Irwin (December 1980)

11. Schiffman, L.G. and Kanuk, L.L. (1994). Consumer Behavior. Prentice Hall, 1994. (ISBN: 0136690033)

12. Swartz, L. N. (1999). Marketing to maturity. International Franchise Association Nov / Dec 1999 Vol.31 No.6, ISSN: 1041-7311.

13. The Thailand News direction Project. (2003). The Report of the Analysis, Situation and Tendency of Thailand, Volume June 2003 [On-line]. Available: http://ttmp.trf.or.th [2004, December 15].

14. United Nations. (1999). International Year of Older Persons. New York: Economic and Social Commission for Asia and the Pacific. 


\section{NOTES}

